\title{
On the Outside Looking Out: an Interview with the Institute for Applied Autonomy (IAA)
}

\author{
Erich W. Schienke ${ }^{1}$ and IAA²
}

\begin{abstract}
This interview with members of the Institute for Applied Autonomy is a discussion of their critically intervening projects and products -projects and products that boldly dip into and out of the socio-technical landscapes that comprise contemporary surveillance systems. Their projects range from constructing robots for activists so as to avoid identification, to building websites for looking up "paths of least surveillance" in Manhattan and London. Threaded throughout the interview is a discussion about the rise of urban surveillance and the rapid transformation of public spaces into privatized places, i.e. "mallification" syndrome.
\end{abstract}

$\underline{\text { 3: Surveillance Cultures and Policies }} \quad \underline{\text { 4: Public Space and Looking Out }}$

\section{Introduction}

The Institute for Applied Autonomy assembled together in 1998 as a group focused on political questions of autonomy and authority within the combined practices of art, engineering, programming and cultural theory. Their first motto "our shit works" was displaced, post nine-eleven, by the urgent slogan "now more than ever!" This begs the question, of course, "what, more than ever?" Further research into the design of tools for autonomy, self-determination, and public critique - particularly over issues regarding the use of public space.

IAA questions and IAA-designed solutions beg, pester and re-configure a culture of surveillance in a manner that is ironic, funny and sometimes cute, but also activist and critical to the core. Alongside the general history and theoretical foundation of the IAA, this interview questions two projects in particular. The first, titled "iSee", is an interactive website for mapping out a path from point A to B through Manhattan (and soon London) that falls under the least surveillance. The second, "GraffitiWriter", is a jacked-up Mars

\footnotetext{
${ }^{1}$ Rensselaer Polytechnic Institute, New York, USA. E-mail: schiee@rpi.edu

${ }^{2}$ For specific information on the IAA and to find a link to the iSee project website go to http://www.appliedautonomy.com/
} 
Pathfinder of a remote controlled hotrod mounted with five orange Kraylon spray paint cans and a $16 \mathrm{~K}$ brain - used for tagging the street, park, or indoor carpet alike. In looking ahead, the IAA's upcoming projects continue to push, refine, and re-imagine assumptions of "technologies for the public."

There is little question about an autonomy applied in the work of the IAA, particularly since their projects (various robots and websites) will sneak off, sometimes without their foreknowledge, and get mentioned in Playboy, hassled by the likes of DARPA chiefs, misappear in ArtByte, run in the streets of Zagreb, and be spotted on Austrian TV spray painting an activist website on the carpet of the Ars Electronica awards ceremony.

In the cultural and geographic shadow of "post nine-eleven", Erich W. Schienke interviewed the Institute for Applied Autonomy (IAA) at Latitude: N 44.6747, Longitude: W 73.9971, on 25 May 2002, for the journal Surveillance \& Society.

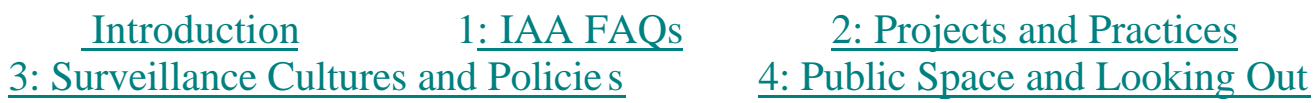

\section{Section 1: IAA FAQs}

Erich: What is the Institute for Applied Autonomy?

IAA 1: We started in 1998. Its a group of people, all of whom have had some kind of connection to technical research environments either working as engineers within those environments or working as artists around those environments - it is those environments that shaped what became the IAA.

E: Would you say you're more technically based than arts based?

I1: We are interested in engaging the technical community but most of what we do is not particularly technical. If talk to engineers about our work, it's not really interesting in terms of the technology we are using. In my mind the thing that is interesting about this work is that it is firmly rooted in both engineering and artistic discourse, and, more importantly, in cultural criticism. We have been consistently interested in bringing these worlds together. If you look at the work we've done, the theme that brings it together is the notion - not too radical - that any technology or product involves a set of social relationships. We initially were interested in the social models that gave rise to robotics industry and science - which have largely been industrial and military. Our work is interesting because we engage these technologies with different sets of concerns, needs and users, and a different relationship between a technology and the community of users it eventually engages. The first thing we were involved with was a project called 'contestational robotics' which was essential trying to take the model of robotics that had emerged from an engineering and military discourse and apply it to dissident groups. Obviously, it's ironic to compare urban environments to battlefields, and to replace human activists with robots. At the same time, we are fairly serious about building tools 
activists can use. I think iSee is an extension of this work, in that it turns the model of policing that is about centralized authoritarian control of urban space on its ear and instead makes surveillance systems transparent to the general public.

I2: That process of turning an established mode of authority on its ear, of inverting it, has been the meta-narrative throughout all of the IAA projects. We are interested in seeing what happens when you do that, like in an engineering context we take a process and work backwards and apply it to another context, such as activism or art.

E: In terms of IAA, if you could call yourselves practitioners of something, what is it that you practice?

I2: That has changed over time. In the early days we were a bit more naive about where it would end up. It helped shaped the projects in a positive way and there was sincerity about where, for instance the GraffitiWriter, was going to go. There was a real belief that they could be manufactured cheaply and easily, and utilized on the street. While we produced a working robot that we used on the street extensively, we weren't able to overcome either the cost or the complexity limitations.

I1: I think it's hard to nail down a definition of our practice, because it continuously evolves - either due to external circumstances, or because of the dynamics within the collective. I think our projects generally play a dual role. On the one hand, they are pedagogical devices that provoke public discussion of critical issues. This conception of work fits neatly within the confines of "art practice." At the same time, our projects are functional tools that dissidents can actually use. In this regard, our work has more to do with engineering (or at least hacker) practice.

E: Projects that are 'autonomous' as you would put it?

I1: I think of what we do as applied critical theory. I really am committed to the idea to create work that does not fall neatly into one of these camps, but that does try to find its own space.

I2: We've always been interested in communicating these ideas in an effective way, whereas critical theory does not do always do that. It communicates it to other critical theorists and to a small group of others outside of that community.

E: Even within art discourse too.

I2: With any of these disciplines this has been the case. We're interested in communicating in a frank way. I mean we go out on the street and people will 'get' the projects in a context that is appropriate and meaningful, that is not watered-down or removed.

I1: It has a lot to do with the kind of impact we're hoping to have and the audiences we are trying to reach. It's one thing to critique engineering culture, but it's another thing 
entirely to engage it directly. To do that, there are things you have to do. For example, it's really important to build stuff.

E: To engage engineers in a way that gets them 'on your wavelength...

I2: They have to respect you enough to listen to you.

I1: We are certainly not the first people to point out problems within engineering discourse. What I think we do that is not as common is to critique engineering culture on its own terms - that is, through the design and fabrication of experimental systems. Similarly, we're interested in public space. So we engage these issues in public, and not only in protected environments - like museums and galleries - where the work never gets seen by the people who most need to see it.

E: What is the most surprising response you have received?

I2: It was surprising from the get-go, once we had the robots, as to how easy it was to engage the engineering audience. That was the foot in the door...and they came to us. They (the engineers) were more excited to talk to us at that point. Within a month or two of completing the robots we ended up giving a plenary talk at the international conference on robotics and automation. That WAS the audience, as far as I was concerned, for engaging robotics discourses.

E: At the source...you were there.

I1: I've been surprised as to how well everything has been received. It is very strange because I think the work we've done is extremely cynical. And it's also a fairly pointed critique of specific people and organizations.

E: Do you think robots are a way for us to displace the cynicism, or embody it in the robot in a way you can talk through it?

I1: I think it's the humor more than it's the robots.

I2: The humor and the aesthetics...that was a part of it from the beginning. It's always been that we need to have a very pointed conversation, but at the same time we're not going to let you know exactly where it's coming from. We want people to ask, is this 'real' or is it not? We try to get that experience to vibrate between those two poles. The content is real, the message is sincere, the robots-they're real, the stuff we say we do - we do. But at the same people see no apparent rational explanation or profit motive, so they just don't understand... (laughing).

E: Like, what, you mean you're autonomous from money? (all laugh)

$$
\underline{\text { 3: Surveillance Cultures and Policies }} \quad \underline{\text { Introduction }} \quad \underline{\text { I: Public Space and Looking Out }}
$$




\section{Section 2: Projects and Practices}

E: How does iSee perpetuate or empower the autonomy of the user?

I1: Theoretically, it allows people to play a more active role in choosing when and how they are recorded by CCTV cameras by providing a means for them to avoid surveillance cams if they want.

I2: None of us think that it's the most effective way to go about it.

E: But it's an example of a method...

I2: Yeah, for me it was more of a discursive tool to provoke a conversation. So, the tool had to work if people are going to take it seriously and really talk about these matters. We had to have something... because it seems like there is a whole genre of art practice about setting up a phoney site or group with the intention of stimulating discourse but its something that is obviously phoney or satirical.

E: Thought experiments can only go so far...

I2: Yeah...before people just filter it out right off. But here's this website that works and the cameras are real. Especially after nine-eleven, everyone is clamoring for more surveillance. So, it became a point of reference within that discourse on accountability and the efficacy of surveillance.

I1: It was interesting to see that, as a point-of-reference, it allowed journalists to talk critically about surveillance. The way journalism works is that there has to be some sort of news angle, and by creating iSee, we provided an opportunity for journalists to address the subject. I had the distinct impression that several of the journalists we talked to were eager are critical thinkers who aren't often able to express themselves in print.

E: They have nothing even to latch on to...

I1: Right, given the structure of journalism it's just not possible. So, in some ways we provide a service to journalists. (laughs)

E: Playing into what journalists need and wants really does open up the discourse. I don't think you can underestimate the importance of that. I mean you guys were mentioned in Playboy, right?

I1 and I2: (chuckle) yeah...

E: How did that come about?

I1: Who knows! They sent us email saying that we had been mentioned in the magazine. 
I2: They didn't contact us until after it went to press.

I1: It was strange, they contacted us requesting a written response to the article. Which was really funny because we had no idea there had been an article... so then they faxed us a copy. We had no idea that it had even happened.

E: When did you have a "eureka" moment on this project? When you said, "Hey, something needs to be done here, this needs to be pointed out" were there any moments or particular situations that struck you?

I2: Surveillance has always been part of our discourse because we've always been focused on public space and the modes of authority that exist in public space. And, it has been one of the things we've been up against.

I1: We certainly have "eureka" moments with the graffiti writer. First let me give some background on the writer. There is a long history of activists using graffiti to distribute messages. The privatization of public space and growth of surveillance systems, along with harsher penalties for getting caught and so forth, makes it increasingly dangerous to write graffiti in highly visible places. So the graffiti writer was intended as a technological solution that could take the place of humans in these areas. Due to surveillance a person can't really go in and tag a bank or a shopping mall, so we intended to make a disposable robot that an activist could use instead. Shortly after completing GraffitiWriter, we brought it to New York for a "reclaim the streets" demo. It was a useful experience at the time because we realized we were not willing to give the robot up.

I2: We had worked on it too much... it was too new at that point.

I1: So later that night we were using it in Washington Square Park and all of a sudden we were approached by a group of graffiti kids and the y were really excited - like, "Dude! Let me see that thing! Wow! I've got to use it" and so forth. We realized that this was the project - to give the robot to total strangers to deface their own neighborhoods. There were other interactions like that. Those types of reactions and moments, though, only seem to happen after the project is built and put in its proper context and actually applying the technology. This is again, why it is so much more interesting to do things outside of the art context. Once you're out in the street doing stuff people have reactions that aren't scripted. People do things you do not anticipate. That allows you to have these moments where you're like "wow, I never thought about that angle" and then you get a whole new interpretation of the project, sometimes even changing its direction.

I2: This is the "applied" part of IAA. We've all watched so many robotics research projects that were developed in a lab, go out to the field they were intended for, and fail miserably. In fact, that's the norm.

E: Because lab conditions are "perfected" conditions... 
I2: ...and there are so many conditions you can't predict.

I1: The labs are like that, but I think the art context is like too. Where people have these very scripted interactions with art objects. No matter what the thing is, if it's happening in an art gallery you pretty much know how people are going to react. They're going to sit there, look at it and think of some sort of intellectualized comment to say.

E: That's why I like to say art thinks for people most of the time. It's meant to have the thought for you, and you build your reactions around it. That's the sort of satisfaction people get out of it... they feel like they had a thought without actually developing it.

E: Are other municipalities adopting iSee? Is it scalable and transferable like that?

I1: It's happening. We're going to England in October to deploy an iSee for London. The people we will be working with there are going out and doing the data collection. That area is sort of the golden chalice for surveillance.

E: ah, yes...

I1: There's also talk about possibly doing one in Amsterdam. The version of iSee that's on the web now was put up very quickly and in some ways was almost a one-off. What we're developing now is a much more general-purpose mapping tool using open-source code. The goal for this is to make a system that other people can take and set up in their own municipalities and use it to monitor surveillance or do whatever kind of localized mapping they want to do. We want to provide a tool that will facilitate that.

E: So this is to become a more general public mapping tool?

I1: That's the longer-term goal for the project.

E: It runs on Linux?

I2: Yeah, and fully open-source.

I1: But it's a Frankenstein of open-source. (laughs)

E: So people will go out with GPS units, or geo-code the info?

I1: The next instantiation of it will be that they have PDA devices. Right now there probably won't be GPS capabilities, but we're trying to find someone to write a plug-in for it. But at the very least they will be able to have a map of the area they are currently in and indicate where various objects are, be they cameras or whatever. That's the main effort now.

E: That's great! So it will be just a visual interface for marking relevant data points. 
I2: Yeah, it'll be mostly a visual interface. But the server will ultimately be able to incorporate data off the GPS receiver and we can add it to the data set.

E: How have you guys been gathering the security camera data in Manhattan? With GPS?

I1: No, no. The set of data points in there now was collected by the New York State Civil Liberties Union. They did a project in 1998 when they went out and made this list of all the security cameras with their locations. Unfortunately, it's woefully outdated. Since then the Surveillance Camera Players have been doing mapping. We're now working with them to get some of their data. We've been talking for a while but will be formally doing the first things together in August to start getting some of their data involved as well.

I2: So, the fact they iSee's initial deployment was Manhattan was merely because that was the only data set available in the world that we knew of. When nine-eleven happened that kind of fed our eternal paranoia about being misunderstood.

E: But that makes you even more 'artistic'... that's great! But seriously, it gave it a much greater impact, thus bringing the whole project into greater relief.

I1: There was a very strange set of circumstances around that project.

I2: We changed our motto from "our shit works" to "now more than ever".

E: Which is a good motto to keep at this point... it's intriguing. Where are you going with the surveillance theme next?

I1: I don't like to talk about things that haven't happened yet, but there are essentially two things happening now. One is to take iSee and develop it more as a generalpurpose mapping tool. The other is takes the third approach to re-contextualizing surveillance technologies I mentioned earlier. That is, I'm particularly interested in radically rethinking the set of relationships between community, police, government, and the like. So, we're working to re-conceptualize these power formulations, and to develop technologies accordingly. I'll be more than happy to talk about that in about eighteen months.

E: Regarding iSee, you couldn't do this without mapping, could you?

I1: It's essentially a mapping application. I'm trying to imagine it without a map and it doesn't make sense. It's tied to physical space and navigating it, but it's not just about navigating. The other thing that happens when you visualize the locations, and more importantly the distributions of all these cameras is that you start seeing what some of the priorities are within thinking about the systems. The way they get marketed are as supposedly effective tools in reducing violent crime, right? But of course the cameras are largely concentrated not so much in residential areas as they are in financial districts. In the US, cameras get largely deployed as a means of protecting property and not people. Inner city and lower income residential neighborhoods with violent crime tend not to get the cameras nearly as much as Wall St. for example where there just isn't a whole lot of 
violent street crime. These are sites though with substantial property holdings.

E: They are supposedly also watching larger scale phenomena too, right? Not just individuals, but group actions, traffic patterns, etc.

I1: Again, it's this phenomena where something interesting happens when you draw a map that allows you to visualize the data in a new way and draw new conclusions about it.

I2: Vision has power.

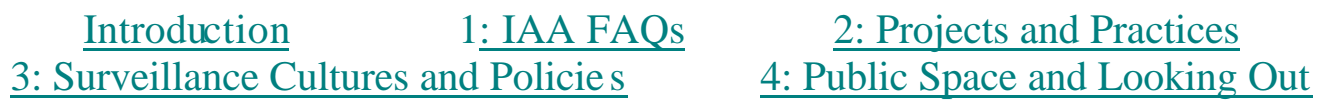

\section{Section 3: Surveillance Cultures and Policies}

E: An obvious reaction and strategy to surveillance, then, is to mark it and avoid it at all costs?

I1: iSee was a quick project that captures a broader research agenda for the IAA. I can imagine at least three ways of re-configuring surveillance systems. The first is to build tools that, as you say, help people avoid cameras. Second is the approach of turning surveillance systems back on the people that control them. This was demonstrated famously in New York by The Shadow newspaper in the 1980s, which published photos of undercover cops. It was a very dangerous thing to be doing as you can imagine. A third approach is to develop alternate uses for video technology in law-enforcement. For example, one of the big problems with CCTV surveillance is that you and I don't know what's being recorded or what's happening to those images and footage. We have no access to it. It's an oversight issue. So, a third way then is to consider ways of deploying CCTV cameras in public space that allow public oversight.

I2: We're looking at the problem of surveillance as an imbalance of power. There are many instances of communities where the police are a 'CONCERN' in that they are not a solution that comes without problems of its own. So, why in that instance do we have the cops in control of the cameras?

E: It's problematic indeed. Particularly in terms of these semi and fully privatized security firms. I find they are even more nerve-wracking than the cops. At least the cops tend to work on predictable patterns... according to law.

I1: Yeah, at least there is the notion that within a public police agency there is - or ought to be - some level of accountability. Obviously, even this claim is controversial. But with privatized security forces the expectation is much lower.

I2: Little things, like the constitution, become irrelevant in that (privatized) environment. Any mechanism for keeping all those flaws in check are just not present. 
E: Is there even much of a long-term threat to criminals because the video could be stored?

I1: Sure, that's the theory and what gets argued. But let's make the distinction between the claims from a company trying to sell these systems and the actual demonstrated capabilities of them. So yes, the claim is certainly being made that by deploying these systems now, sometime down the road we will be able to catch terrorists in the act or potential terrorists. CCTV advocates will tell you that is that it hasn't proven effective because it hasn't been deployed very widely yet. "Just you wait and we'll get the evidence" is the attitude to that, but I'm not convinced. Study after study has shown that the face-recognition technology that these systems depend on is a long way from being reliable.

I2: Also, it relies on pre-emptively knowing who terrorists are.

E: Established on racial profiling and such.

I2: Mostly they're pulling from FBI database of mug shots and what not. But if you place a high enough premium on having a clean identity, you won't be detected and those are the people who will be carrying out the tasks.

I1: You're already starting to see a response. Such as in an article in the NY Times about a month ago that about dummy cameras. Dummy surveillance systems, apparently, work just as well as fully functional systems.

E: Really?

I1: Because they work as deterrents. The main effect they seem to have is as a deterrent.

I2: Like scarecrows.

I1: That is one argument surveillance companies will then make-that simply having the camera there will prevent or deter the crime. Which is simply not the case, the crime will simply be displaced... the criminal will go somewhere else. Which usually means a move to residential neighborhoods that don't have as many cameras.

E: If it's only a deterrent then why not just buy a nice looking box?

I1: Precisely, and there are companies that sell really nice boxes that don't do a damn thing and are a fraction of the cost.

E: Amazing what a conspicuously placed useless box, piece of glass, and blinking light can do.

I1: I can't quote verse and chapter at the moment, but there were several small studies trying to get at the psychological impact of living with video surveillance for a long time. 
What is the impact of feeling like you are constantly being monitored? If dummy cameras are effective they are only so because people believe they are being monitored. A dummy camera is nice because you avoid issues of oversight. There is no data and you don't have so much a concern with cost because they're dirt-cheap. But you still have this set of concerns dealing with the question of the long term psychological and social effects of feeling like you're constantly under surveillance.

E: I'm surprised we've gotten this far without mentioning 'Panopticon'. Something that rarely ever gets mentioned about Bentham's design in regards to security cameras, and this was brought up by someone at a conference I recently attended, is that the prisoners in their cells are supposed to be back-lit. Most people only refer to the element that doesn't allow you to know if you're being watched but rarely does the issue of the backlighting of the prisoners ever come up. I'm not sure what the equivalent to backlighting would be here, but I'm led to suspect that it's the threat that the images can be stored over time, recycled and be made to be held accountable for over time. Time and temporal accountability become the backlighting here.

I1: More essentially it is the notion that you do live without privacy.

E: I am wondering if there is much camera-freaking going on out there? You've got to imagine that there are going to be sociological responses to this in that people will mask. Masking in the sense that they dress up or put on another personae for a specific task they don't want to be detected for. Something a little more complex than pulling a pair of nylons over your head, but not much. I'm wondering too if you think fashion is going to respond to surveillance.

I2: I think it's already happening, but in terms of surveillance as a sign of status. As in, "I'm important enough that I need to be surveyed." We're completely primed for that if we're not already in fact there. The webcam phenomenon is a small part of that. Ankle bracelets, identifying with prison culture-all of those things play into it.

E: Which is huge in the States. I'm not sure if people who would read this outside the US understand how big prison culture is here.

I2: Movies make surveillance look really cool too. The only thing cooler than say shooting a guy on the corner is an overhead black and white surveillance shot of the guy getting killed on the corner.

E: Pretty soon it'll be from a satellite none-the-less. I remember a John Shirley short story written in the early 90s called "Jody and Annie On TV" where a Bonnie and Clyde like couple would do murders just to get on TV. Then they would get each other off (sexually) while watch it being reported on TV. Speaking of TV, there's a TV show on in the UK with a Michael Moore like host that asked people to send in tapes of their CCTV performances because you are supposed to be able to request footage of yourself at an exact time and place-by a camera of course. However, I heard they were getting barely any entries because no one was getting their requested tape back from the CCTV system. 
I1: Now in the UK people are doing a protest sort of performance where they are getting themselves caught on as many cameras as they can and requesting the footage. Under British law they have the right to request to the footage. I suppose the idea there being that if you make a lot of requests it will gum up the works.

E: On public cameras only, right.

I1: Yeah, yeah... so there are people trying to do this as a defiant act or something. (chuckles)

E: It is interesting though, at least as a way to test the system to see how responsive or closed it is.

I2: I think the kind of intuitive apprehension a lot of us feel about surveillance is getting more and more lost. The idea of a lot of those type of projects rely on trying to shock people as to the extent surveillance is pervasive. That's just gets less and less effective as people seem more than happy to accept that everything they do is being surveyed all the time. Take this webcam phenomena for example, a fair portion of younger people over the past few years have spent their developmental youth in front of a webcam, and performing in front of a camera, and there's this whole exchange of file types of personal performances people have done on cameras. Or wishing they hadn't done that thing on camera because now everybody has access to it and it keeps playing over and over again. Those people are never going to be shocked about anything to do with surveillance.

I1: One of the things that is so interesting about it to me is that we are losing this sense of public indignation and outcry against the surveillance. It is being couched as this dualism between privacy on one hand and security on the other. That to me seems like a good opportunity for a critical intervention. There are a couple of ways to cut it. One is to make the efficacy argument - i.e. to point out that we're not really gaining a heck of a lot of security. The other component too is this psycho-emotional question of whether people actually feel safer living under constant surveillance. I'm not sure, but I don't think there has been a whole lot of research into that question. I can see a hypothetical argument why people, under a lot of circumstances, might not actually feel more secure because every camera you see is somehow a reminder that you are actually in danger or jeopardy because that's why the camera need to be there. It seems there can be a parallel drawn between this and people who watch a lot of TV. Research has shown that people who watch a lot of TV tend to have this view of the world as being an inherently dangerous place. People who don't watch a lot of TV don't share this view, largely because they are out in that supposedly dangerous world (as opposed to experiencing it through the filters of police dramas and the evening news). I suspect a similar thing could be going on with people that see a lot of cameras.

E: It becomes a circular reification in that because we see so many cameras the world must be a dangerous place, therefore it needs to be surveyed. 
I1: Sure. They must be there for a reason- it's because there is a lot of crime out there, or because people are inherently dangerous and can't be trusted, or there are terrorists around every corner.

I2: It takes any kind of agency or responsibility that an individual citizen might have out of the question. Then you place your trust in this mechanism that you have no connection to. It has no accountability to you. It relies on fear as the overwhelming force, rather than co-operation. Any of the traditional social values we like to associate democracy with in America-all of those things become really unnecessary.

E: Into the aether. What about accountability here? It seems to be the biggest thing missing on any side of the camera-accountability through extending a public awareness and increasing the transparency of these systems, but more importantly a deeper accountability on the other side of the camera. At least is making these systems a bit more transparent and less a "shuttered box" would be a first step.

I2: But the companies building these systems are obviously not going to do that.

I1: At least not on their own accord. One kind of solution that gets proposed is this notion of a civilian review board.

E: To build public participation into the design process of these systems?

I1: Yeah, but again it's worth thinking carefully about how that participation is structured. Is the answer really another layer of bureaucracy on top of this technology the best solution? I suspect not. Other kinds of approaches at making these much more open and transparent systems are particularly interesting to me and worth looking at. The question of how you go about getting these systems deployed is an interesting one because you have to make very convincing and fairly nuanced argument as to why this is important. Again, keep in mind that the way most people are thinking about this is that they are trading their privacy for security. As long as the debate continues to be couched in those terms I think it's going to be very difficult to push for reform or any kind of alternatives to these models. System design is part of it, but another important component is to challenge that privacy/security foundation of surveillance. I think that is going to be key.

E: Have you noticed any major differences between the US and Euro attitudes towards surveillance?

I2: I wish I could say they were...

I1: There are, but they seem subtle. I'm also hesitant to make broad sweeping generalizations, particularly about Europe.

I2: In London surveillance was primarily motivated and argued, in terms of the media, by local terrorism from the likes of the IRA. 
I1: The landmark case for CCTV in London was not a terrorist case, but a kidnapping case.

I2: But that was after the system was deployed, wasn't it?

I1: At that point it was deployed in a very limited way. That case played a key role in getting that system then deployed throughout London. They supposedly had a case where 'the camera' had caught 'the killer'. Of course in actuality that wasn't the case.

I2: It was like a picture of Bigfoot, it was all blurry and from the distance.

I1: That's how these cameras get used, once you've come up with a suspect, then you can use the camera to identify the assailant.

I2: As a forensic tool.

I1: Once they knew who they were looking for and roughly where and when he committed the crime, then they can turn to the footage in this area and say, oh, there he is. But it's just not that easy.

I2: Like we can say Mohamed Attah went into McDonalds because we saw it, but we can't catch Mohamed Attah because he went to McDonalds and was caught on camera. (laughs)

I1: Security in London, and Israel as well, was most certainly motivated by terrorism and until recently that was just not the case here in the US. Terrorism here was always a more abstract principle.

E: We still have very limited experiences with terrorism, and certainly a very limited structure for it. You only need to visit our airports compared to those in say Germany to understand how fucked up our systems still are, particularly domestically. The difference was disconcerting.

I1: The cultural differences are interesting too. The kinds of themes I would point to more generally have to do with culture. Like in Europe public space seems like a much more valuable concept as opposed to the US. There is a more established, or at least more vocal, community in Europe that is much more critical of surveillance.

E: It seems in Europe there is more of a general desire and tradition for public participation in public systems design. Whereas in the US, more so recently, these systems seem to be able to get implemented by fiat without any sort of significant public participation.

I1: Yeah, they have a public hearing. People give their gripes, bitch and moan and companies then go ahead doing business as usual without giving public feedback much mind. 
I2: One cultural distinction is that in the US we rely on street cops and the presence of street cops, at least traditionally. Whereas in the UK at least you don't have that kind of armed police presence constantly patrolling. They're much more willing to rely on videotape and going back through footage. If you look at the way protests are handled in the US vs. the UK, the differences are obvious. After the June 18th protest in the UK a few years back they just put up a website with people's pictures on them. The public could go there and look at the pictures of the protestors. If you recognized someone you knew there you could click on their picture and then fill out a form giving their name. That was it. That was how they were retroactively trying to catch people who were breaking windows and whatnot. Whereas in the US we treat protests as a military operation that either needs to be contained or squelched.

E: There are good examples where surveillance is useful, no?

I2: Sure. But like any other technology we're concerned with the imbalance of power that results in it being held by one or even several institutions with a similar agenda.

E: I wonder how much talking is going on between these surveillance networks. A lot of these systems are privatized and sight specific, but I wonder what sort of transfer or aggregation of information, if any, is going on behind the scenes in these privatized networks?

I2: It's like a map. It doesn't have an inherent ethic to it as a tool, but the one who makes the first map owns the territory. If you see someone making a map of you, you begin to get ask, "Hey, what are you up to?"

E: "Hey, you lookin' at me?" (imitating DeNiro in 'Taxi Driver’)

I2: Exactly. The same apprehensions happen with the genome project when a single corporation wants to hold that data as opposed to a socialized body that it making the data public as they go.

E: Wouldn't that be nice...?

$\underline{\text { 3: Surveillance Cultures and Policies }} \quad \underline{\text { Introduction }} \quad \underline{\text { 4: Public Space and Looking Out }}$

\section{Section 4: Public Space and Looking Out}

E: What are some of the other constraints on public space, besides surveillance, that you've been working with?

I2: There are the social factors that constrain people from interacting with other people. The idea with "Little Brother" was to get around certain problems in traditional modes of 
activism. You know, you go into the "public space", because that's where the "people" are, and you bring your message to the "people", however unpopular to them, and so on. That's how democracy works. But there's all these other extenuating factors. From a very young age you learn to avoid people the often look like activists-who have the funny hair, ripped jeans and piercings in their face. You know, all that stuff.

E: Don't take candy from these people...

I2: Avoid people that look strange. So, with "Little Brother" we recast activism within the context of a cute robot. Using the very things about 'cuteness' that attract people. Large eyes relative to the size of the nose and mouth, large hands, things you associate with babies, baby animals, and things that are comforting. Things that are plain old cute.

E: Looking for the cuteness gene...

I2: What we found with that project was that we actually could get the same content to an audience of children to senior citizens-precisely the same people that would avoid activists because of their appearance.

I1: Barriers to effective public space may be cultural, legislative, or technical. One of the other themes we are touching on is privatization. Particularly in the U.S., what has been considered public space is largely disappearing. What passes for public space now are places like shopping malls which are privately owned.

E: Markets are becoming the main public space.

I1: Well, in some senses markets always have been.

E: I mean it in the sense that everything that is public is being, somehow through advertising and such, made into a market.

I1: Until recently, the rules of a public space - such as some protection for free speech had applied to marketplaces. But now these places are becoming privatized. You can't walk into a mall with protest signs-they'll kick you out and there's no legal problem with that. One of the key functions of public space within a healthy society is to be a place where people tend to congregate, where you can have a free exchange of ideas, and encounter those that may not be like you. As public spaces disappear, they are replaced by privatized ones that do not play these roles. It's not just the legislative issues. If you look at the way shopping malls are designed, each mall is designed with a specifically defined plan about which people are supposed to shop there. There are upscale malls and downscale malls. It's another example of increasing economic and social segregation.

E: Down to the width of the checkout counters.

I1: Yeah, there are these great maps that show where the customers were meant to come from for each mall. You get these overlapping circles - a lot of it is geographic as people 
aren't expected to drive more than 20 or so minutes to get to a place to shop. But it's also an economic and social demarcation as well, particularly where there are two malls next to each other people aren't expected to go to both. So, it's part of this much broader phenomena of increasing social segmentation through the privatization of these spaces.

E: Thus diminishing the chances even more for people of different social groups to interact.

I1: This has real implications for a democratic and pluralistic society. That's unpacking a lot, but the tie-in to us is that we're very concerned with this notion that privatization is robbing us of this historically important cultural phenomena. One of the things we have been trying to do with these projects is to, in some small way make those private spaces function as traditional public spaces. We do what we can do. It has been a theme through a lot of our work. This gets back to what we were talking about earlier, regarding the issue of surveillance, that there are differences between public uses of surveillance as opposed to private uses. How does that shape the use and social experience of public surveillance when the space is private and also the police or law enforcement is privatized? I think it changes the game quite a bit and in ways that nobody has a handle on yet. Because all of these issues ownership of the images recorded, distribution of those images, access to those images by people being filmed in them-these are very much unsolved legal issues.

E: Do you think there will be a resolution to these issues at some point?

I2: At some point, but not likely in our favor. (laughs)

I1: Legal issues like these do tend to get resolved over time, of course.

E: They could stay gray areas though.

I1: My guess is that they will become resolved as we have more experience with issues of surveillance and ownership of the data.

I2: People are going to have to be upset with a situation in order for them to want it to be any different.

I1: More to the point, there has to be a lawsuit or a series of lawsuits. I can see a few places where it could happen. There have already been these examples where surreptitiously recorded surveillance images have been distributed through either the internet or commercial products, including pornography. As that continues to happen you will see more of these court cases where people question what right an entity has to distribute information without people having a choice in the matter.

I2: Whether or not this will turn into policy changes, who knows?

E: I suspect that'll a long time coming, and enforcing those policy issues is a whole other 
problem entirely.

I2: Yeah. The important thing about public space is that it's where you find people that aren't like you, from your economic class or a different ethnicity, like a monkey island where everyone passes through. That's been, politically, the value of it. Where you can post a message to people that may not already be on your side. That's what we mean when we talk about discourse. When we were discussing earlier the discourse between disciplines that wasn't 'the game'. The game is to reach people who disagree with us in an effective way. That's where the issue of humor and aesthetics play a major role. How do you have that critical discourse with someone who already disagrees with you, but you don't want to let them know that they do. Or, you keep them laughing and keep the conversation going at the same time.

I1: Yeah, and to get back to the question you raised about surveillance and policy. There has been one set of criticisms that have to do with the policy issue and there will be increasing pressure, hopefully, to change policy based on those concerns. The other set of critiques that are having and will continue to have an effect are those questioning the efficacy of surveillance. So far the studies have been, at best, inconclusive in proving that the deployment of these systems actually reduces crime rates. The argument can be made that, in a meaningful way, these systems don't work. They particularly don't work in the kinds of crimes used to justify their existence. Specifically, for things like terrorism, they have had no impact at all that anyone has been able to point to or define. With regards to nasty and violent crimes, murder, rape and so forth, there is no reason to believe that the cameras have any real impact. They do tend to have an impact on nuisance level crimes like panhandling or loitering. But that, again, is more of a deterrent more than any real means of achieving prosecution. So, this starts to raise a different separate set of questions. Look, these are fairly expensive systems that cost tens of thousands of dollars to employ.

E: Particularly municipally.

I1: With demonstrably very little actual effect.

$\underline{\text { 3: Surveillance Cultures and Policies }} \quad \underline{\text { Introduction }} \quad \underline{\text { I: Public Space and Looking Out }}$

